\title{
Correction to: Circular RNA YAP1 inhibits the proliferation and invasion of gastric cancer cells by regulating the miR-367-5p/p27 Kip1 axis
}

Hui Liu ${ }^{1+}$, Yuan Liu ${ }^{1 \dagger}$, Zhaolian Bian ${ }^{2 \dagger}$, Jing Zhang ${ }^{1 \dagger}$, Rui Zhang ${ }^{1}$, Xiaoyu Chen ${ }^{1}$, Yanxia Huang ${ }^{1}$, Yang Wang ${ }^{3}$ and Jinshui Zhu ${ }^{1 *}$

\section{Correction to: Mol Cancer \\ https://doi.org/10.1186/s12943-018-0902-1}

After the publication of this work [1], a spelling error was found: the ID of the circRNA, termed circYAP1, in the original publication was misspelled as "has_circ 0002320". The corrected spelling is "hsa_circ_0002320". We sincerely apologize for the spelling error; however, it does not affect any of the interpretations or conclusions of the article.

\footnotetext{
Author details

'Department of Gastroenterology, Shanghai Jiao Tong University Affiliated Sixth People's Hospital, No. 600 Yishan Road, Shanghai 200233, China. ${ }^{2}$ Nantong Institute of Liver Disease, Department of Gastroenterology and Hepatology, Nantong Third People's Hospital, Nantong University, Nantong 226006, Jiangsu, China. ${ }^{3}$ Medical School of Nantong University, Nantong 226006, Jiangsu, China.
}

Published online: 09 July 2019

\section{Reference}

1. Zhu, et al. Circular RNA YAP1 inhibits the proliferation and invasion of gastric cancer cells by regulating the miR-367-5p/p27 Kip1 axis. Mol Cancer. 2018;17(1):151.

\footnotetext{
*Correspondence: zhujs1803@163.com

${ }^{+}$Hui Liu, Yuan Liu, Zhaolian Bian and Jing Zhang contributed equally to this work.

'Department of Gastroenterology, Shanghai Jiao Tong University Affiliated Sixth People's Hospital, No. 600 Yishan Road, Shanghai 200233, China Full list of author information is available at the end of the article
}

(c) The Author(s). 2019 Open Access This article is distributed under the terms of the Creative Commons Attribution 4.0 International License (http://creativecommons.org/licenses/by/4.0/), which permits unrestricted use, distribution, and reproduction in any medium, provided you give appropriate credit to the original author(s) and the source, provide a link to the Creative Commons license, and indicate if changes were made. The Creative Commons Public Domain Dedication waiver (http://creativecommons.org/publicdomain/zero/1.0/) applies to the data made available in this article, unless otherwise stated. 